\title{
Modeling of wind turbine vortex generators in considering the inter-effects between arrays
}

Zhao, Zhenzhou; Shen, Wenzhong; Wang, Ruixin; Wang, Tongguang; Xu, Bofeng; Zheng, Yuan; Qian, Siyuan

Published in:

Journal of Renewable and Sustainable Energy

Link to article, DOI:

$10.1063 / 1.4997039$

Publication date:

2017

Document Version

Publisher's PDF, also known as Version of record

Link back to DTU Orbit

Citation (APA):

Zhao, Z., Shen, W., Wang, R., Wang, T., Xu, B., Zheng, Y., \& Qian, S. (2017). Modeling of wind turbine vortex generators in considering the inter-effects between arrays. Journal of Renewable and Sustainable Energy, 9(5), [053301]. https://doi.org/10.1063/1.4997039

\section{General rights}

Copyright and moral rights for the publications made accessible in the public portal are retained by the authors and/or other copyright owners and it is a condition of accessing publications that users recognise and abide by the legal requirements associated with these rights.

- Users may download and print one copy of any publication from the public portal for the purpose of private study or research.

- You may not further distribute the material or use it for any profit-making activity or commercial gain

- You may freely distribute the URL identifying the publication in the public portal 


\section{Modeling of wind turbine vortex generators in considering the inter-effects between arrays}

Zhenzhou Zhao, Wenzhong Shen, Ruixin Wang, Tongguang Wang, Bofeng Xu, Yuan Zheng, and Siyuan Qian

Citation: Journal of Renewable and Sustainable Energy 9, 053301 (2017); doi: 10.1063/1.4997039

View online: http://dx.doi.org/10.1063/1.4997039

View Table of Contents: http://aip.scitation.org/toc/rse/9/5

Published by the American Institute of Physics

\section{Articles you may be interested in}

Study on variable pitch strategy in $\mathrm{H}$-type wind turbine considering effect of small angle of attack

Journal of Renewable and Sustainable Energy 9, 053302 (2017); 10.1063/1.4989795

In search of the wind energy potential

Journal of Renewable and Sustainable Energy 9, 052301 (2017); 10.1063/1.4999514

Regulating power management in interconnected microgrids

Journal of Renewable and Sustainable Energy 9, 055502 (2017); 10.1063/1.5003003

Study and comparison between two DTC strategies of induction machine fed by direct matrix converter Journal of Renewable and Sustainable Energy 9, 055501 (2017); 10.1063/1.5002769

Measurements of heat and humidity fluxes in the wake of offshore wind turbines Journal of Renewable and Sustainable Energy 9, 053304 (2017); 10.1063/1.5003811

Unsteady Navier-Stokes studies on loads, wake, and dynamic stall characteristics of a two-bladed vertical axis wind turbine

Journal of Renewable and Sustainable Energy 9, 053303 (2017); 10.1063/1.5003772 


\title{
Modeling of wind turbine vortex generators in considering the inter-effects between arrays
}

\author{
Zhenzhou Zhao, ${ }^{1,2, a)}$ Wenzhong Shen, ${ }^{2}$ Ruixin Wang, ${ }^{1}$ Tongguang Wang, ${ }^{3}$ \\ Bofeng Xu, ${ }^{1}$ Yuan Zheng, ${ }^{1}$ and Siyuan Qian ${ }^{1}$ \\ ${ }^{1}$ Energy Technology Engineering Research Center of Ministry of Education of Renewable, \\ Hohai University, Nanjing, Jiangsu Province 210098, China \\ ${ }^{2}$ Department of Wind Energy, Technical University of Denmark, Lyngby 2800, Denmark \\ ${ }^{3}$ Jiangsu Key Laboratory of Hi-Tech Research for Wind Turbine Design, Nanjing University \\ of Aeronautics and Astronautics, Nanjing, Jiangsu Province 210016, China
}

(Received 20 July 2017; accepted 23 August 2017; published online 18 September 2017)

\begin{abstract}
Vortex generators (VGs) are commonly placed on wind turbine blades to delay flow separation in the boundary layer. VGs can be parametrically modeled in computational fluid dynamics for effective and efficient simulations of wind blade flow fields. Many researchers have studied the vortex circulation created by VGs and created various parametric models used with the Navier-Stokes equations, but most of them are based on a single winglet of VGs and do not include the intereffects between the winglets. This paper proposes a parameterized VG array model based on counter-rotating VGs, which properly takes into account the inter-effects between winglets. Two cases, i.e., a plate with a pair of VGs and a DU-W2-250 blade segment with five pairs of VGs, are investigated to validate this model; the array type parametric model is in closer agreement with experimental data than traditional models. Compared to the solid VG model, the array type model has similar streamlines and surface pressure coefficients on the suction surface. The array type VG model can effectively reduce the number of grid points and yield highly accurate predictions of wind turbine blade aerodynamic characteristics. Published by AIP Publishing. [http://dx.doi.org/10.1063/1.4997039]
\end{abstract}

\section{INTRODUCTION}

In China, the onshore sites of new wind energy projects are categorized as "low wind sites" because most onshore sites with high winds have already been well-established. Sites with a low mean wind speed require a different approach to wind turbine design compared to high wind sites, for both onshore and offshore markets ( $\mathrm{Li}$ and $\mathrm{He}, 2013)$. The onshore market also involves upgrading a large number of old wind turbines that were built 10 or even 20 years ago, and designing new wind turbines that can extract more energy from lower-speed winds. Vortex generators (VGs) which were originally introduced by Taylor in 1947 represent one way of such upgrade for the onshore market (Stam, 2016).

VGs consist of small winglets mounted on the upper surface of the blade with an angle to the incoming flow. Flow past the VGs creates a tip vortex, which draws the energetic, rapidmoving outside air into the slow-moving boundary layer in contact with the surface (Bragg and Gregorek, 1987). A turbulent boundary layer is less likely to separate than a laminar one and is therefore desirable to ensure effective control of the blade loading (Lin et al., 1994). VGs are applied on wind turbine blades to delay or prevent the separation of flow, reduce drag (particularly pressure drag), increase blade lift force, and upgrade the power output of the wind turbine on the whole. There are several kinds of VGs, but the most commonly used ones in wind

${ }^{\text {a) }}$ Author to whom correspondence should be addressed: joephy@163.com 
engineering are small delta wings that are mounted in the inner part of the blade and at positions between 10\% and 30\% chords on the suction side (Timmer and Van Rooij, 2003).

Computational fluid dynamics (CFD) is a useful approach to research VG aerodynamics. Several studies have shown that the size, shape, position, angle of attack (AoA), and other VG characteristics significantly impact the wind blade performance (Fernandez et al., 2012). Structural and position parameters must be carefully determined either experimentally or by CFD. VGs are very small compared to wind turbine blades, and their heights are close to that of the boundary layer (Rao and Kariya, 1988). In a fully gridded CFD, the mesh in the region of VGs must be refined carefully in order to acquire precise flow field information. It is timeconsuming and labor-intensive to refine the mesh and improve the mesh quality sufficiently, and the number of necessary grids is so excessive that even simulating a short blade section calls for a great deal of hardware resources-let alone simulating a full size multi-MW wind blade (Troldborg et al., 2015).

Alternatives to modeling VGs with solid boundaries include modeling the VG shape directly, modeling the shedding vortex profile created by the VG, and statistical CFD methods (Booker and Zhang, 2009 and Zhang et al., 2011). Bender et al. (1999) proposed the "BAY" model, in which a small number of grid cells were used to model VGs; the forces of fluid exerted by VGs distributed evenly on every grid cell and were added as source terms into the Navier-Stokes (N-S) equations. This model does not readily reveal the locations of grid cells containing the VGs, however. Jirásek (2004) modified this model to "jBAY," in which VGs are replaced by non-thickness sheets. In these two models, the strength of shedding vortices from the tip of VGs does not need to be estimated and forces acting on the flow by VGs are empirically determined.

Kunik (1986) proposed an approach to model the shape of the VG shedding vortex and accurately simulated VGs by adding vorticity into the vortex dynamics equation as a source term. Bray (1998) developed a simple calculation model for VG circulation based on the lifting line theory and experimental data but could only roughly estimate the strength of the shedding vortex. Wendt and Reichert (1996) built a semi-empirical equation for circulation to model VGs mounted on symmetric airfoil sections. May (2001) considered the velocity profile of a Lamb-Oseen vortex as the source of the secondary flow field vortex and set the profile directly on the relevant grid cells. These researchers effectively considered the image effect of the vortex due to the blade surface, but there has been little research to date on improving the vortex strength estimation method. Wendt (2004) found that the velocity profile of the shedding vortex is similar to that of a Lamb-Oseen vortex-their characteristic parameters are the maximum circulation and maximum vorticity. Booker and Zhang (2009) modeled the vortex generation in CFD without meshing VGs but adding source terms to the governing equations to create vortices; their focus was larger-scale applications such as the use of vortices for force enhancement. They established a large-scale VG source term model by giving the distribution of tangential velocity and axial velocity to create the VG shedding vortex but were not able to sufficiently improve the circulation of the shedding vortex, and the source term was limited in the cylindrical region, in which the tangential velocity in the boundary layer is discontinuous.

Other researchers explored statistical methods by transforming the effect of VGs from threedimensional (3D) into two-dimensional (2D) combined with the 2D N-S equations as an additional source term. In 2005, Nikolaou et al. (2005) used the 3D N-S equations that essentially describe the complex flow around a VG configuration, where a statistical spanwise averaging procedure was applied to obtain an equivalent set of $2 \mathrm{D}$ equations enriched with extra source terms. However, they largely neglected the circulation strength of the VG shedding vortex.

The vortex system is comprised of the main factors contributing to the VG characteristics. Accurately modeling their effects as-imposed on the flow field is necessary to establish a suitable and reliable vortex model. Zhang et al. (2011) proposed a parameterized model for the deltawing type VGs in which the shedding vortex circulation is calculated based on the delta wing theory. They mainly focused on a mono-VG wing and validated the model with counter-rotating VGs. Troldborg et al. (2015) modeled VGs equipped with a $10 \mathrm{MW}$ rotor using a modified version of the BAY model similar to that used by Jirásek, and also for a single wing. Traub (2001) and Pauley and Eaton (1988) researched the aerodynamics of a group of delta wings and VGs to 
find that differences in the gap between the two wings result in different vortex effects; in other words, models must appropriately account for the interaction of both VG winglets.

In this study, VGs are modeled by considering the inter-effect of vortex systems of two winglets. The proposed model is established by coupling Prandtl's lifting line theory with the leading-edge suction analogy proposed by Polhamus and Biot-Savart's law. This model is validated by first comparing VG plate circulation in plates between simulated and experimental results and then applying it to simulate VG arrays mounted on a DU91-W2-250 blade section.

\section{FUNDAMENTAL THEORY}

\section{A. Lifting line theory}

According to the lifting line theory developed by Prandtl in the early 20th century, the wing is modeled as a single bound vortex line located at the $1 / 4$ chord position with an associated shed vortex sheet (Houghton et al., 2013). The local bound circulation changes along the lifting line from $-b / 2$ to $b / 2$ as shown in Fig. 1 .

A free stream with a velocity $U$ flows from "-" to " + " in the x-direction; $b$ is defined as the spanwise length of the wing, and $\Gamma(y)$ is the local circulation of the bound vortex (Fig. 1). According to the vortex conservation law, the shedding of a vortex filament is created downstream due to the spanwise change in $\Gamma(y)$. The shedding vortex induces a downwash velocity in the lifting line. The downwash velocity at the point $\mathrm{P}\left(\mathrm{y}_{0}\right)$ in the lifting line can be expressed as follows:

$$
w\left(y_{0}\right)=-\frac{1}{4 \pi} \int_{-b / 2}^{b / 2} \frac{d \Gamma / d y}{y_{0}-y} d y .
$$

The angle between the resultant velocity and the downwash velocity is commonly called the "downwash angle," $\alpha_{i}$, which is specified as

$$
\alpha_{i}\left(y_{0}\right)=\arctan \frac{w\left(y_{0}\right)}{U} \approx \frac{w\left(y_{0}\right)}{U} .
$$

Note that " $\alpha$ " is the geometrical angle between the airfoil chord and the free stream velocity. Due to the downwash angle, an effective AoA, $\alpha_{\text {eff }}$, exhibits the following relationship:

$$
\alpha_{e f f}=\alpha-\alpha_{i}\left(y_{0}\right) \text {. }
$$

The airfoil lift coefficient, $C_{L}$, is expressed as follows:

$$
C_{L}=C_{L .2 D}^{\alpha}\left(\alpha-\alpha_{L=0}\right),
$$

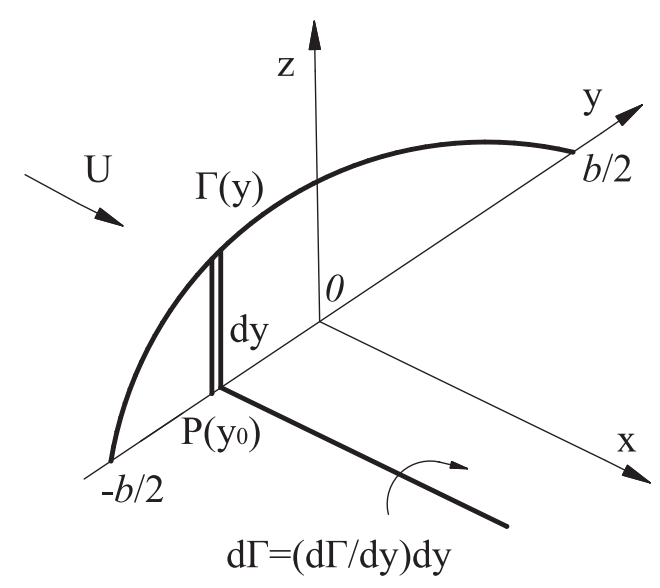

FIG. 1. Schematic view of the lifting line theory. 
where $C_{L .2 D}^{\alpha}$ is the slope of the airfoil lift coefficient, the subscript $L$ represents the lift, and $\alpha_{L=0}$ is the zero-lift AoA. According to the Kutta-Joukowski theory

$$
\rho U \Gamma(y)=\frac{1}{2} \rho U^{2} \times C_{L} \times c(y) .
$$

The final circulation equation of $\Gamma(y)$ along the spanwise direction is

$$
\Gamma(y)=-\frac{1}{2} U \times C_{L} \times c(y),
$$

where $c(y)$ is the local chord of the wing.

\section{B. Leading-edge vortex lift of a delta wing}

The delta wing is triangular in shape and has a low aspect ratio. Wind-tunnel studies on sharp-leading-edge delta wings have shown that even at a relatively low AoA, the flow separates from the leading edges and rolls up into two-spiral vortex sheets adhered to the surface (Fig. 2). The potential flow theory does not consider the effect of the two-spiral vortex, which produces two high negative pressure fields on the upper surface of the delta wing. Negative pressure is responsible for a sizable portion of the lift; the total lift of the delta wing equals the sum of (1) the attached stream or "potential-flow lift" and (2) the separated leading-edge spiral vortices or "vortex lift" (Polhamus, 1971). The total lift coefficient $C_{L}$ of the delta wing can be written as follows:

$$
C_{L}=C_{L . p}+C_{L . v}
$$

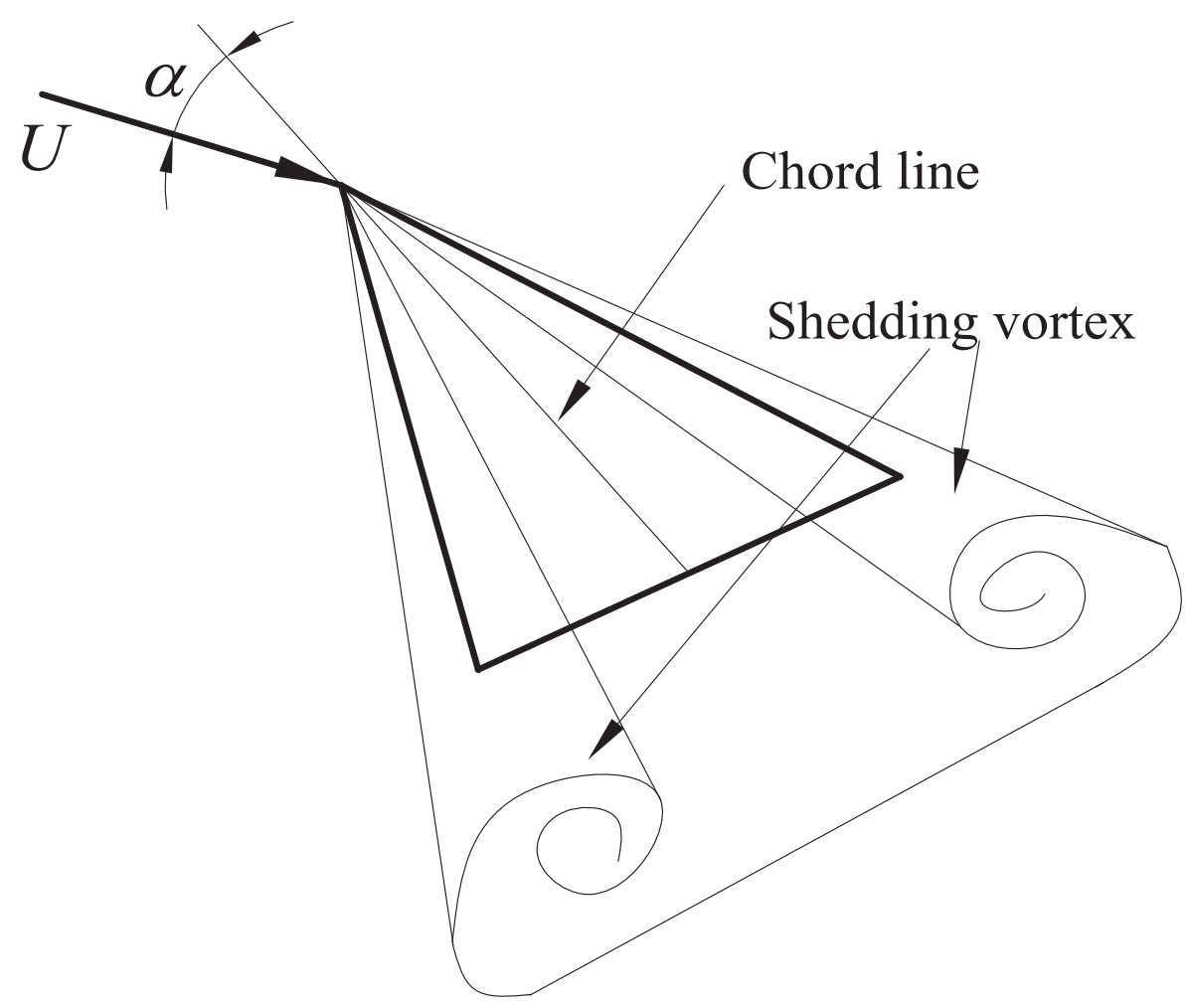

FIG. 2. Illustration of the delta wing theory. 


$$
C_{L}=K_{p} \sin \alpha \cos ^{2} \alpha+K_{v} \cos \alpha \sin ^{2} \alpha,
$$

where $C_{L . p}$ is the lift coefficient determined by potential lift, $C_{L . v}$ is the lift coefficient of vortex lift, and $K_{p}$ and $K_{\mathrm{v}}$ are constants.

\section{PARAMETRIC MODEL OF VG ARRAYS}

\section{A. Modeling vortex profiles}

The parameterized vortex model of VGs is added to the N-S momentum equations as a source term to simulate the effect of VGs on wind blade aerodynamics. There are several vortex solutions for the N-S equations, including the Potential vortex, Rankine vortex, LambOseen vortex, Taylor vortex, and Batchelor vortex. Among these models, the Lamb-Oseen vortex is best able to reflect real vortex structures (Zhang et al., 2011). The vortex flow is not constant due to dissipation. The Lamb-Oseen vortex sufficiently counts the flow viscosity and variations in the vortex with time. The initial circulation consumed is $\Gamma_{0}$, and the ongoing circulation is expressed as follows:

$$
\Gamma=\Gamma_{0}\left[1-\exp \left(-\frac{r^{2}}{4 \nu t}\right)\right] .
$$

The velocity distribution of a Lamb-Oseen vortex is

$$
\begin{aligned}
V_{\theta}(r) & =\frac{\Gamma_{0}}{2 \pi r}\left[1-\exp \left(-\frac{r^{2}}{4 \nu t}\right)\right], \\
r_{0} & =\sqrt{4 \nu t}
\end{aligned}
$$

where $\Gamma_{0}$ is the maximum shedding vortex circulation, $r$ is the distance from the vortex core, $\nu$ is the kinematic viscosity, and $t$ is the timescale. The magnitude of Lamb-Oseen vortex velocity decreases with time, and at a certain point, most of the energy is concentrated in the core within $r^{2}<4 \nu t$ (Fig. 3).

The Lamb-Oseen vortex is chosen as the vortex model in our N-S equation. In Eqs. (9) and (10), the maximum circulation $\Gamma_{0}$ is the key parameter in the velocity and circulation profiles.

\section{B. Circulation of a single delta wing}

There are two categories of VG arrays, co-rotating and counter-rotating, consisting of several wings (Fig. 4) (Godard and Stanislas, 2006). Counter-rotating VGs are composed of several pairs of wings which are inclined in the opposite direction with respect to the flow. Here, one pair of wings is considered our research object.

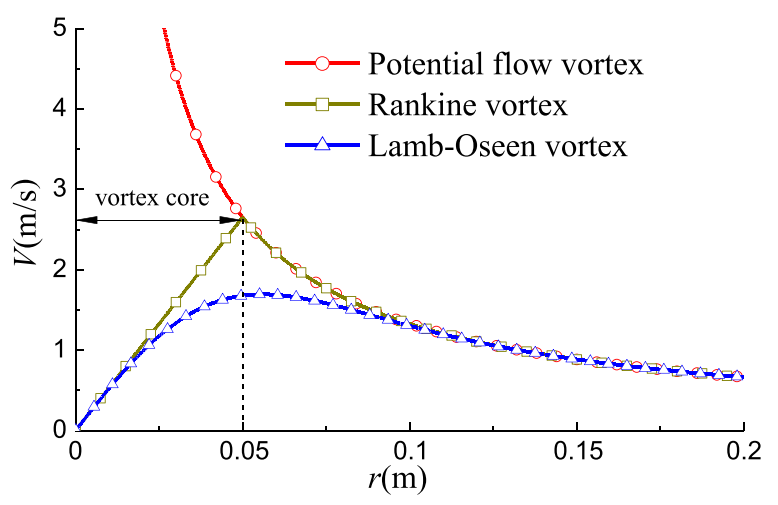

FIG. 3. Velocity profiles of different vortex models. 

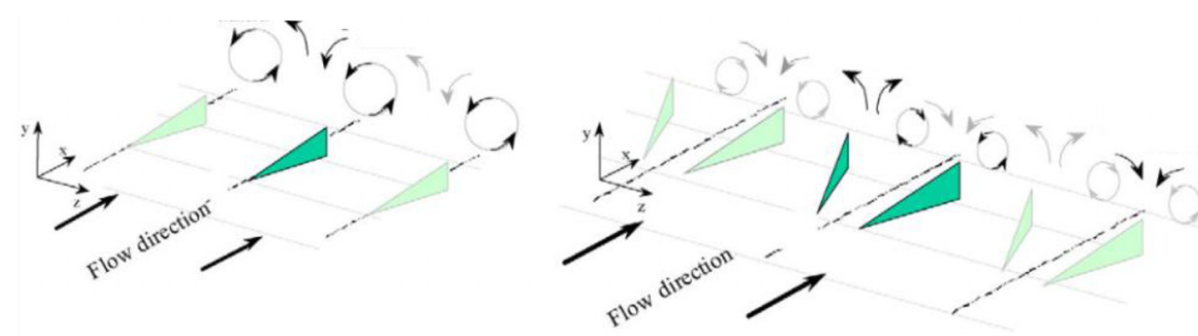

FIG. 4. Co-rotating and counter-rotating VG arrays.

Figure 5 shows a schematic diagram of two counter-rotating VGs composed of two half-delta wings, VG1 and VG2. The height of the half-delta wing is $b 1=b 2=b / 2$. Because the VG is so small, the lifting line is located in the midline position (Traub, 2001); the distance of two midlines is $\mathrm{Z}$, and the circulations of the lifting lines of VG1 and VG2 are marked as $\Gamma_{1}$ and $\Gamma_{2}$, respectively. " $a$ " is the length of the line connecting $\mathrm{P}_{1}$ and $\mathrm{P}_{2}$ which are any two points located in the two lifting lines, and " $\beta$ " denotes the angle between the plane and the line of $\mathrm{P}_{1} \mathrm{P}_{2}$.

Jones' (1946) slender wing theory indicates that the attached flow spanwise load distribution on a slender delta wing is elliptic. Therefore, for VG1 or VG2, the spanwise load distribution is given by

$$
\Gamma=\Gamma_{0} \sqrt{1-(2 y / b)^{2}}
$$

For elliptic loading, the lift is written as Eq. (12) according to the Kutta-Joukowski theory. The effective vortex span of the delta wing is $\frac{\pi}{4}$, and so,

$$
L=\rho \frac{\pi}{4} U \Gamma_{0} b=C_{L .3 d}^{\alpha} \sin \alpha \frac{1}{2} \rho U^{2} S,
$$

where $C_{L .3 d}^{\alpha}$ is the lift curve slope. $S$ is the geometric area of the wing and $S=1 / 2 \times b \times c$, which yields the maximum circulation of a delta wing

$$
\Gamma_{0}=U c C_{L .3 d}^{\alpha} \sin \alpha / \pi
$$

\section{Effects of the shedding vortex system of the VG2 wing}

At point $\mathrm{P}_{1}\left(\mathrm{y}_{1}\right)$ on $\mathrm{VG} 1$, the vortex system of $\mathrm{VG} 2$ induces a velocity characterized by its bound and shedding vortexes. The shedding vortex of VG2 induces a downwash velocity at the lifting line of VG1.

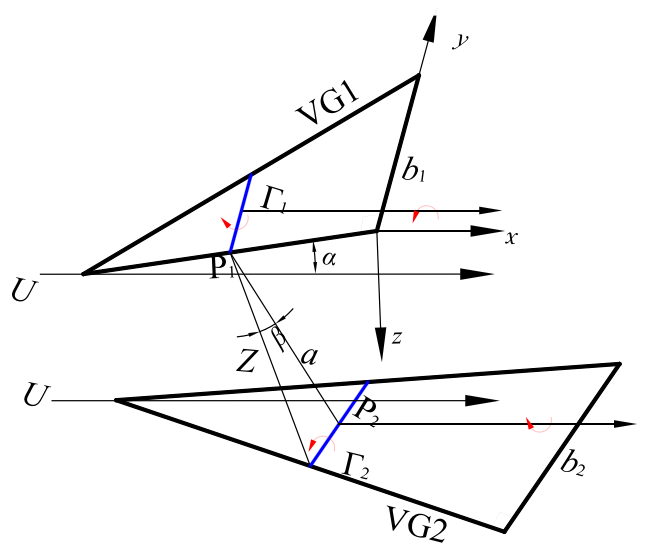

FIG. 5. Schematic diagram of VGs composed of VG1 and VG2. 
The velocity in $\mathrm{P}_{1}\left(\mathrm{y}_{1}\right)$ of VG1 due to a strip of the shedding vortex of VG2 can be calculated by Biot-Savart's law

$$
d v_{12 T}=\frac{-1}{4 \pi a}\left(\frac{d \Gamma_{2}}{d y_{2}} d y_{2}\right) .
$$

The vertical component of this velocity is

$$
d w_{12 T}=\frac{-1}{4 \pi a}\left(\frac{d \Gamma_{2}}{d y_{2}} d y_{2}\right) \sin \beta .
$$

As shown in Fig. 5, the following relationships facilitate further analysis:

$$
\begin{gathered}
\sin \beta=\frac{y_{2}-y_{1}}{a}, \\
a=\sqrt{\left(y_{2}-y_{1}\right)^{2}+Z^{2}} .
\end{gathered}
$$

Equations (15)-(17) indicate that the normal velocity at $\mathrm{P}_{1}\left(\mathrm{y}_{1}\right)$ due to the shedding vortex sheet of VG2 is Eq. (18) considering the image effect

$$
w_{12 . T}=\int_{-b_{2}}^{b_{2}} \frac{-1}{4 \pi a^{2}}\left(\frac{d \Gamma_{2}}{d y_{2}} d y_{2}\right)\left(y_{2}-y_{1}\right) .
$$

For an elliptic spanwise load distribution, this expression is singular at the wing tips $( \pm b / 2)$. This can be circumvented by integrating other parts, noting that the circulation tends to zero at the wing tips, and thus,

$$
w_{12 . T}=\int_{-b_{2}}^{b_{2}} \frac{-1}{4 \pi} \Gamma_{2} \times \frac{a^{2}-2\left(y_{2}-y_{1}\right)^{2}}{a^{4}} d y_{2} .
$$

The downwash angle of VG1 can be expressed as follows:

$$
\alpha_{12}\left(y_{1}\right)=\frac{w_{12 T}}{U}=\int_{-b_{2}}^{b_{2}} \frac{-1}{4 \pi U} \Gamma_{2} \times \frac{a^{2}-2\left(y_{2}-y_{1}\right)^{2}}{a^{4}} d y_{2} .
$$

The effect of the downwash on lift can be calculated by using an equivalent 2D lift curve slope in the lifting line theory described in Sec. II. The effect of the induced downwash causes a rotation of the local flow so that the wing operates at an effectively reduced AoA

$$
\begin{gathered}
\alpha_{\text {eff }}=\alpha-\alpha_{12}, \\
C_{L .2 D}^{\alpha}\left(\alpha-\alpha_{12}\right)=C_{L .3 D}^{\alpha} \alpha=C_{L},
\end{gathered}
$$

where $C_{L .2 D}^{\alpha}$ is determined by the $2 \mathrm{D}$ aerofoil, and $C_{L .3 D}^{\alpha}$ is determined by the aerodynamics of the wing. For elliptic loading, the following relationships hold:

$$
\begin{gathered}
C_{L .2 D}^{\alpha}\left(\alpha-\alpha_{\mathrm{i}}\right)=C_{L .3 D^{\alpha}}^{\alpha}=C_{L}, \\
\alpha_{\mathrm{i}}=-C_{L} / \pi \lambda,
\end{gathered}
$$

where $\lambda$ is the aspect ratio of the wing. Considering the image effect of the vortex at the blade surface, $\lambda=b / c$,

$$
C_{L .2 D}^{\alpha}=\frac{C_{L .3 D}^{\alpha}}{1+C_{L .3 D}^{\alpha} / \pi \lambda}
$$


For a delta wing, $C_{L .3 D}^{\alpha}$ is closely approximated as follows (Traub, 1997):

$$
C_{L .3 D}^{\alpha}=4 \tan ^{0.8} \varepsilon,
$$

where $\varepsilon$ is the wing apex angle.

For the change in the attached flow, the lift of VG1 due to VG2 is

$$
C_{L \cdot 12}=\frac{2}{b_{1}} \int_{0}^{b_{1} / 2} C_{L .2 D}^{\alpha}\left(y_{1}\right) \alpha_{12}\left(y_{1}\right) d y_{1} .
$$

\section{Effect of the bound vortex of the VG2 wing}

As shown in Fig. 5, the bound vortex of VG2 induces an axial velocity component at the lifting line of VG1. The induced axial velocity can be written as follows:

$$
\begin{gathered}
d u_{12 \cdot \mathrm{b}}=\frac{-\Gamma_{2} \cos (\beta)}{4 \pi a^{2}} d y_{2}, \\
u_{12 . b}=\int_{-b_{2}}^{b_{2}} \frac{-\Gamma_{2}}{4 \pi} \frac{Z}{a^{3}} d y_{2} .
\end{gathered}
$$

By taking into account this induced velocity, the effective axial velocity becomes $U_{\text {eff }}$ $=U+u_{12 . b}$ and a new lift curve slope $C_{L .3 D \text {.new }}^{\alpha}$ emerges as

$$
C_{L}=C_{L .3 D . n e w}^{\alpha} \alpha=\frac{\rho\left(U+u_{12}\right) \Gamma_{1}}{1 / 2 \rho U^{2} S} .
$$

The total potential lift coefficient of VG1 is expressed as follows:

$$
C_{L . P}=C_{L .3 D \text {.new }}^{\alpha} \alpha-C_{L .12} \text {. }
$$

To ensure an consistency with Polhamus's formulation (Polhamus, 1966), the effect of net potential lift of VG1 should be recast as an effective 3D lift-curve slope given by

$$
K_{P}=C_{L \cdot \mathrm{p}} / \sin \alpha
$$

\section{E. Comprehensive impact of the VG2 vortex system}

In Polhamus's solution (Polhamus, 1966) for vortex lift, $K_{V}$ is affected by the lift-curve slope of the wing and the wing's aerodynamic efficiency, $\partial C_{D} / \partial C_{L}^{2}=1 / \pi \lambda$. The deviation from an elliptic loading can be incorporated via an efficiency factor $\sigma$, which represents the increase in vortex drag from the upswept planar minimum. Thus, the expression of $\partial C_{D} / \partial C_{L}^{2}=$ $(1+\sigma) / \pi \lambda$ can be used for a wing with a non-elliptic loading.

The shedding vortex of VG2 induces a drag of VG1 at point $\mathrm{P}_{1}\left(\mathrm{y}_{1}\right)$, and the drag coefficient is

$$
C_{D .12}=\frac{\int_{0}^{\mathrm{b} 1 / 2} \rho U \alpha_{12}\left(y_{1}\right) \Gamma_{1}\left(y_{1}\right) d y_{1}}{1 / 2 \rho U^{2} S} .
$$

For an elliptic loading wing, the monoplane vortex drag for VG1 can be written as follows:

$$
C_{D . V G}=\frac{\left(C_{L .3 D \cdot n e w}^{\alpha} \alpha\right)^{2}}{\pi \lambda} .
$$


The efficiency factor used to account for the effect of VG2 on the drag of VG1 is

$$
\sigma_{12}=C_{D .12} / C_{D . V G}
$$

Thus, the vortex lift constant for VG1 including the effects of VG2 can be written as follows:

$$
K_{V}=\frac{C_{L .3 D \text {.new }}^{\alpha}-C_{L .3 D \text {.new }}^{\alpha}\left(1+\sigma_{12}\right) / \pi \lambda}{\cos \Lambda},
$$

where $\Lambda$ is the wing leading edge sweep angle.

Based on the above mentioned analysis and Eqs. (8), (13), (32), and (36), the final maximum circulation of VG1 in VG arrays is

$$
\Gamma_{0}=\frac{U c \sin \alpha}{\pi} \times\left(K_{P} \cos ^{2} \alpha \sin \alpha+K_{V} \sin ^{2} \alpha \cos \alpha\right) .
$$

\section{SOURCE TERM DETERMINATION}

CFD simulations were conducted using the Fluent software, which has a user-defined function (UDF) as an entry to add source terms to the N-S equations.

In an annular region with inner radius $r$, outer radius $r+\mathrm{d} r$, and length $L$, the axial flow velocity at the entrance equals $U$ and the tangential velocity equals zero (Fig. 6). When the flow leaves the region, the axial velocity remains constant and the tangential velocity becomes $V_{\theta}$. Using the angular momentum theorem, the torque suffered by the annular region equals the change in angular momentum

$$
d M=d F \cdot r=\rho U V_{\theta} r d A
$$

where $d M$ is the torque subject on the annular region and $\mathrm{d} A$ is the sectional area.

The terms in the momentum equation should be a volume fraction, and so, the force in Eq. (38) should be divided by the volume of this region as follows:

$$
F(r)=\frac{d F}{L d A}=\frac{\rho U}{L} V_{\theta} .
$$

In a Cartesian coordinate system, the force components are

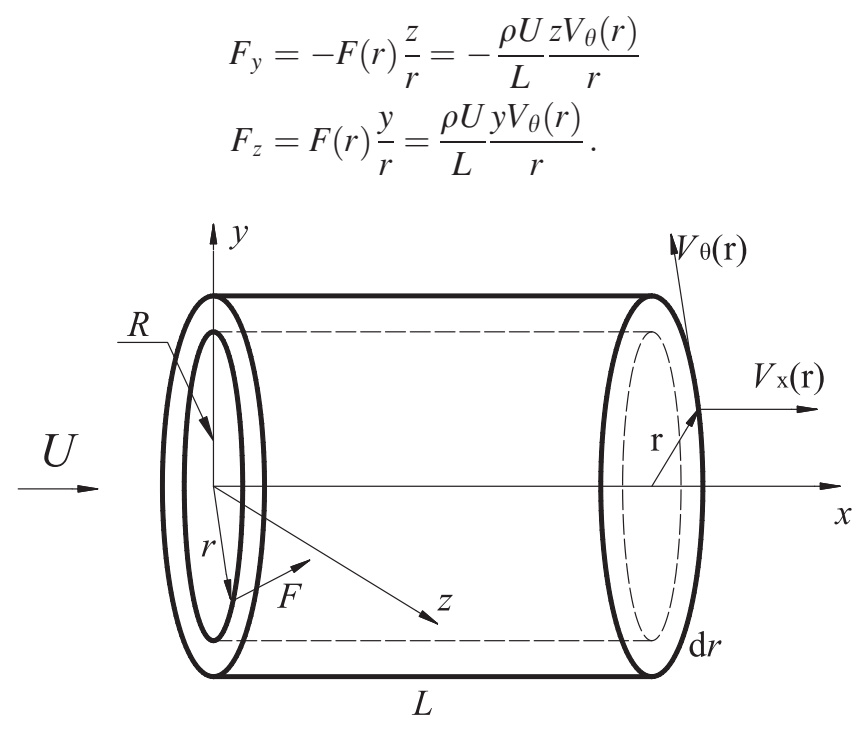

FIG. 6. Annular source force region. 
The surface of the blade exerts a significant impact on the induced vortex of VGs and alters the velocity. Our treatment consists of an image vortex which reflects the modeled vortex on the solid surface (Bray, 1998), as shown in Fig. 7.

After considering the image effect, the force of the Lamb-Oseen vortex can be written as follows:

$$
F(r)=\frac{\rho U}{L}\left(V_{\theta}+V_{\theta i m}\right)
$$

Then, according to Eq. (10), Eq. (42) is given as

$$
\begin{aligned}
& V_{y}=\frac{\Gamma}{2 \pi} \frac{z-z_{0}}{r^{2}}\left[1-\exp \left(-\frac{r^{2}}{4 \nu t}\right)\right]-\frac{\Gamma}{2 \pi} \frac{z-z_{0}}{r_{i m}^{2}}\left[1-\exp \left(-\frac{r_{i m}^{2}}{4 \nu t}\right)\right] \\
& V_{z}=-\frac{\Gamma}{2 \pi} \frac{y-h}{r^{2}}\left[1-\exp \left(-\frac{r^{2}}{4 \nu t}\right)\right]-\frac{\Gamma}{2 \pi} \frac{y+h}{r_{i m}^{2}}\left[1-\exp \left(-\frac{r_{i m}^{2}}{4 \nu t}\right)\right] .
\end{aligned}
$$

The axial force changes as the axial velocity changes due to the drag of VGs. The energy absorbed by flow curling and the VG arrangement are difficult to specify without appropriate experimental or numerical methods. The CFD results corresponding to the axial drag taken from a horizontal line probe passing through the vortex center on a plane normal to the streamwise direction can be fitted to a Gaussian distribution. The same results were also obtained by Zhang (2011) and Filgueira et al. (2017). Thus, the drag distribution of a VG following a Gaussian function is given by

$$
f(x)=\frac{1}{\sqrt{2 \pi} \sigma} e^{-\frac{(x-\mu)^{2}}{2 \sigma^{2}}},
$$

where $\mu$ is the mean value and $\sigma$ is the standard deviation. The Gaussian distribution naturally lends a probability of 0.95 within two standard deviations of the mean, reflecting the nature of the vortex core, where almost all the energy of the vortex as well as the drag is concentrated. If the total drag of a VG is $D$, the average drag will be $D / L$. The drag distribution on a plane normal to the vortex axis can be analyzed according to the Gaussian distribution. $s$ is defined as the area of a circle around the vortex core

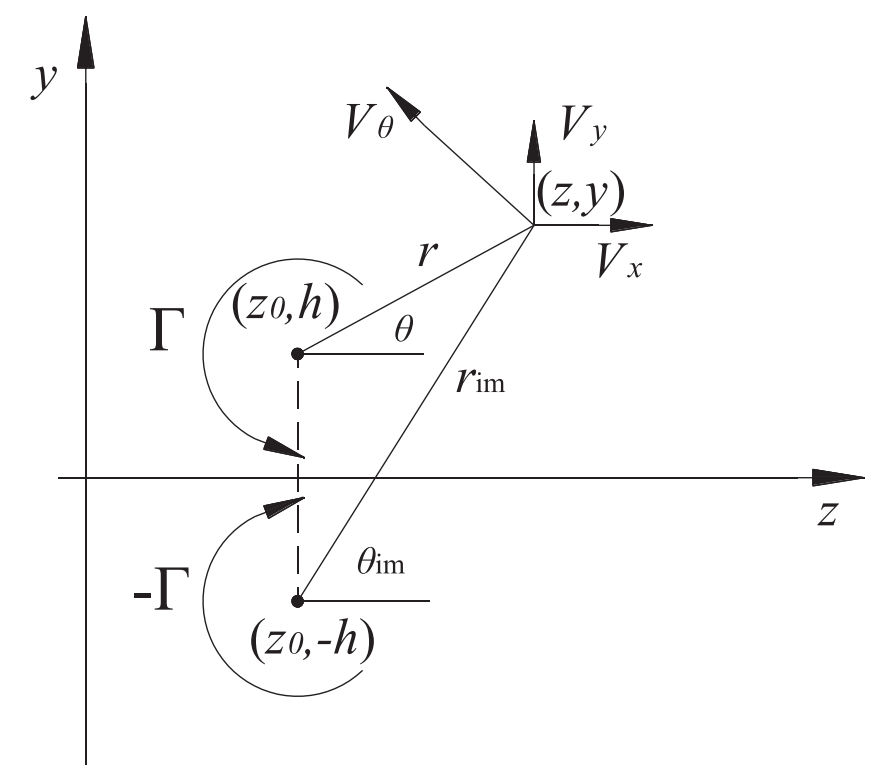

FIG. 7. Potential flow model of a real and image vortex. 


$$
s=\pi r^{2}
$$

On the boundary of the vortex core, $s_{0}=\pi r_{0}^{2}$ and $r_{0}^{2}=4 \nu t$. The drag effects on the flow are near the region $s \in\left[0, s_{0}\right]$ corresponding to $x \in[0,2 \sigma]$ for the Gaussian distribution, and so,

$$
\sigma=\frac{s_{0}}{2}=\frac{1}{2} \pi r_{0}^{2} .
$$

By substituting Eq. (45) to Eq. (43), the force distribution is given by

$$
\frac{F_{x}}{D / L}=\frac{2}{\sqrt{2 \pi} \pi r_{0}^{2}} \exp \left(-\frac{2 r^{2}}{\pi^{2} r_{0}^{4}}\right) .
$$

The value of integration of Eq. (46) is 1 in the range of $x \in\left[-\frac{L}{2}, \frac{L}{2}\right]$ or $r \in[0, \infty]$; the resulting drag distribution is

$$
F_{x}=\frac{2 D}{L \sqrt{2 \pi} \pi r_{0}^{2}} \exp \left(-\frac{2 r^{2}}{\pi^{2} r_{0}^{4}}\right)
$$

The forces $F_{x}, F_{y}$, and $F_{z}$ are known, and so, the energy source term can be expressed as follows:

$$
k=\vec{F} \cdot \vec{V}=F_{x} \cdot V_{x}+F_{y} \cdot V_{y}+F_{z} \cdot V_{z} .
$$

\section{APPLICATIONS AND ANALYSIS OF THE ARRAY TYPE MODEL}

The VG array model is validated using a two-step process. First, the maximum circulation is calculated and compared against the results of other models and experimental data. Next, the model is applied to a simulation on a wind blade section of an aerofoil DU 91-W2-250, and these results are compared against the CFD results with solid VG boundaries.

\section{A. Applying the VG array model on a plate}

Pauley and Eaton (1988) investigated the principle of the VG shedding vortex in the turbulent boundary layer using a group of VGs with a height of $2 \mathrm{~cm}$ and a chord of $5 \mathrm{~cm}$ at a wind speed of $16 \mathrm{~m} / \mathrm{s}$ in a typical wind tunnel. The maximum circulation is calculated via the approaches described by Bray (1998), Wendt (2004), and Zhang et al. (2011), and the results are compared against the experimental data (Pauley and Eaton, 1988) and the results of the other models (Fig. 8). The array type model is in closer agreement with the experimental data than the other models. From the experimental data, it is found that the VG circulation varies nonlinearly as AoA increases; the circulation grows to a lesser extent once AoA exceeds $18^{\circ}$. Bary's results, conversely, suggest that the growth increases at larger AoAs. The Wendt curve is very similar to that of the single VG model proposed by Zhang et al. (2011), and both their circulations vary linearly versus AoA and gradually deviate from the experimental results. At low AoAs $\left(4^{\circ}-18^{\circ}\right)$, the array type VG model yields accurate predictions; the maximum error is within $4.8 \%$, and the maximum error is $13.2 \%$ even at an AoA of $20^{\circ}$. The maximum error of the single VG model reaches $49.4 \%$ at an AoA of $20^{\circ}$.

VG2 induced a downwash angle and a smaller effective wind speed. Both factors contributed to a smaller lift and a smaller circulation, the effects of which grow stronger as AoA increases. The array type model reflects these phenomena very well. The advantage of the array type model is more obvious from the curves of circulation versus distance at an AoA of $18^{\circ}$ (Fig. 9). Because Bary, Wendt, and Zhang models do not take interactions into account, their circulations remain constant as spacing increases. There is apparent growth in the results of the 


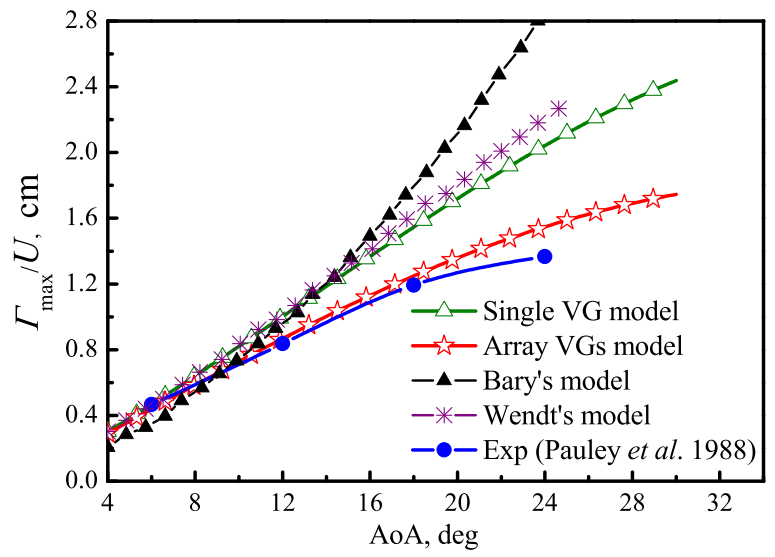

FIG. 8. Curves of VG circulation versus AoA.

array type model and experimental data as $0.2 \leq Z / c_{\mathrm{r}} \leq 1$ (where $\mathrm{Z}$ is the distance between two winglets and $c_{\mathrm{r}}$ is the winglet root chord), however. As $Z / c_{\mathrm{r}}>1$, the vortex effect is markedly reduced due to the large spacing, which also changes the circulation.

\section{B. Applying the array type VG model on the wind turbine blade}

The DU 91-W2-250 aerofoil was designed by Delft University. The maximum thickness is $25 \%$ chords, and its location is at $32.2 \%$ chords. The blade segment shown in Fig. 10 has a spanwise length of $0.175 \mathrm{~m}$ and a chord of $0.6 \mathrm{~m}$ with five pairs of VGs at $20 \%$ chord (Timmer and Van Rooij, 2003). The chord of the delta winglet of the VGs is $17 \mathrm{~mm}$, its spanwise length is $5 \mathrm{~mm}$, the distance between the two winglets is $10 \mathrm{~mm}$, and the AoA of the winglets is $16.4^{\circ}$ (Fig. 11). For convenience, all modeled structures are identical to the experimental structures. A source term of the circulation is added in the $20 \%$ chord zone as shown in Fig. 12. After grid sensitivity verification, the mesh in modeling VGs with solid boundaries is $3 \times 10^{6}$ (but only $0.8 \times 10^{6}$ is used for the parametric modeling). In the VG domain, the height of the first layer grid is $1 \times 10^{-5} \mathrm{~m}$ and the grid growth rate is 1.1 , which guarantees $\mathrm{y}^{+} \leq 1.5$. The $\gamma-\operatorname{Re}_{\theta t}$ transition model based on an SST $k-\omega$ turbulence model was used for these simulations, as it is known to yield highly accurate predictions (Zhao et al., 2015, 2016).

Figure 13 shows a comparison between the results of the array type model and the single VG model. When $0^{\circ} \leq \mathrm{AoA} \leq 14^{\circ}$, the two simulation results are in good agreement with the experimental data (demarked as Exp, VGs). When $14^{\circ} \leq \mathrm{AoA} \leq 18^{\circ}$, the curves of the array type VG model agree much better with the experimental data than those of the single VG

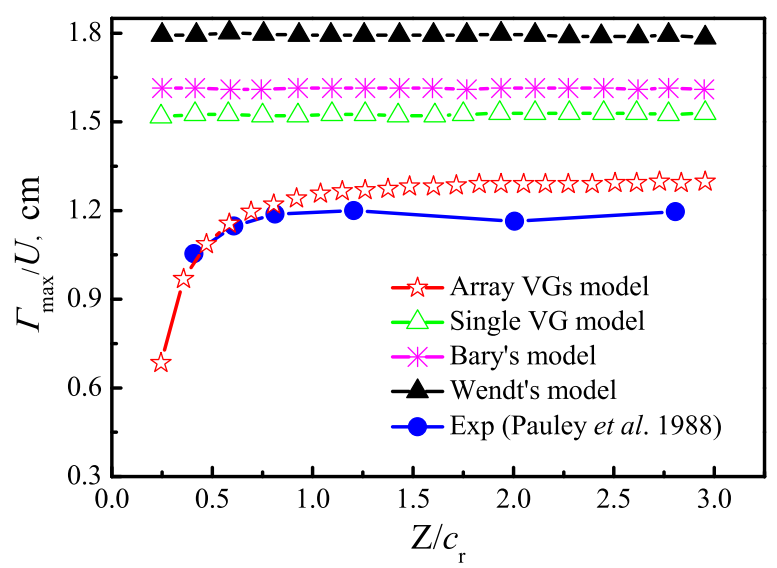

FIG. 9. Curves of VG circulation versus winglet spacing. 


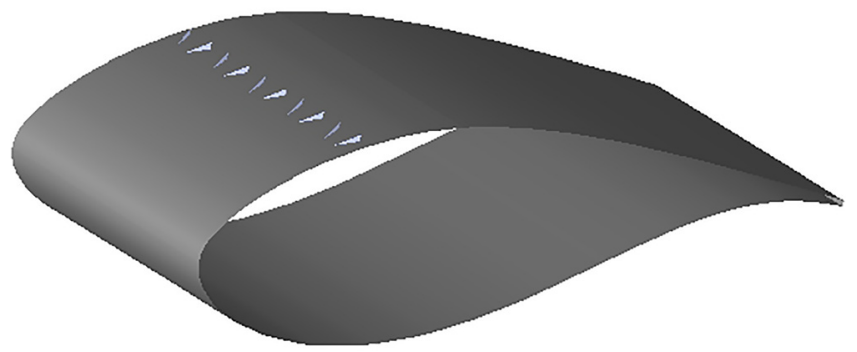

FIG. 10. DU 91-W2-250 blade segment.

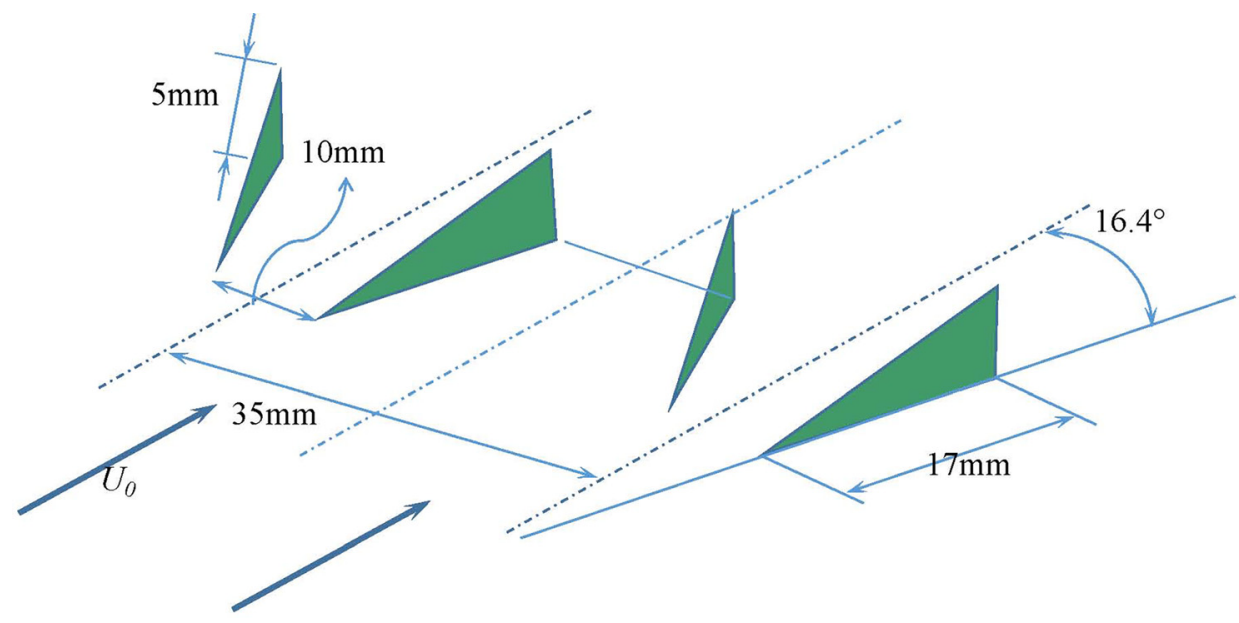

FIG. 11. VGs structure parameters.

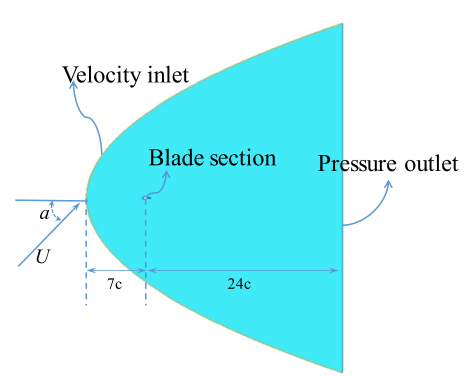

(a)

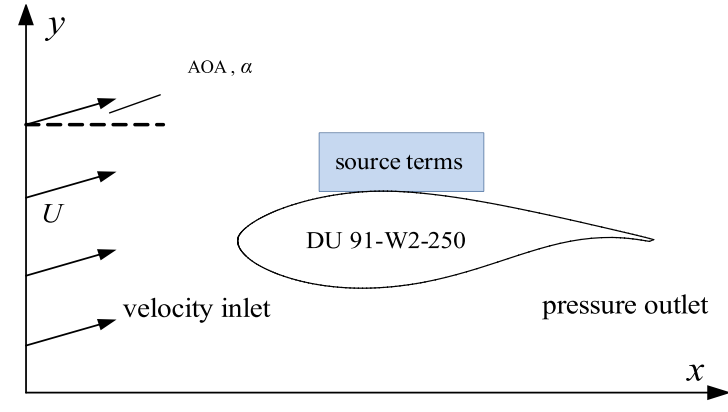

(b)

FIG. 12. Source term setting in the array type VG model.

model. This can be explained by the circulations resulting from the two models. The single VG model overestimates the circulation and thus overestimates the lift coefficients of the blade segment. At higher AoAs, the inter-effect of wings is stronger, and thus, the degree of overestimation is higher.

Figure 14 shows the streamlines above the upper surface of the blade segment at an AoA of $16^{\circ}$, where the streamline distribution fields are similar. In the model with VG solid boundaries, fluid does not flow through the solid wall and the VGs spoil the streamline. This phenomenon is not observed in the array type VG model results. The array type VG model generates a shedding vortex which transports the far-wall air with the high energy to the near wall, effectively suppressing the flow separation. The array type VG model without meshing VGs can thus replace the solid VGs in CFD simulation. In addition, the different colors of the 


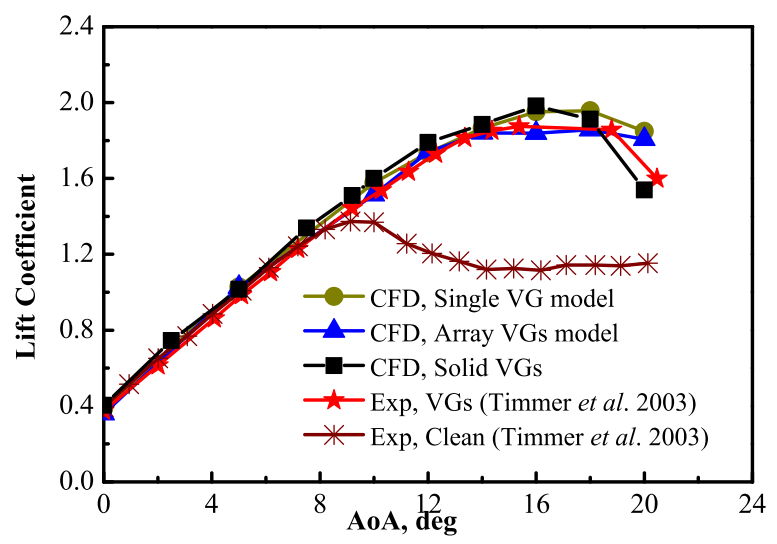

FIG. 13. Comparison of lift coefficient distributions of CFD and experiment.

streamlines show the differences in the velocity; the red color shown in the leading edge means the bigger velocity and the blue color in the trailing edge is smaller velocity. The distribution of the color indicates the tendency of velocity variation.

Figure 15 shows the vortex structures of the two models at three AoAs $\left(5^{\circ}, 12^{\circ}\right.$, and $\left.18^{\circ}\right)$. The models yielded similar results. At $\mathrm{AoA}=5^{\circ}$, the laminar flow is spoiled by VGs, which creates a turbulent flow flowing downstream. The flow field in the downstream area varies periodically in the spanwise direction and has a much lower velocity nearer the trailing edge. At $\mathrm{AoA}=12^{\circ}$, the two models yield nearly identical results. Low-speed zones appear in the middle of the chord, and the parameterized model has a more complex vortex field. At $\mathrm{AoA}=18^{\circ}$, both models predict that the upper surface encounters a separation in the end and middle of the chord.

Figure 16 shows a comparison of pressure coefficients between the CFD with solid VGs and the CFD with parameterized VGs. At $\mathrm{AoA}=5^{\circ}$ and $\mathrm{AoA}=12^{\circ}$, the pressure coefficients between both models are very similar; this explains why their lift coefficients are also very close (Fig. 13). At AoA $=18^{\circ}$, the pressure coefficients upstream of the VGs closely agree with each other. After the VGs, there were some notable differences between the two models. The fluid field becomes much more complex when air separation occurs at AoA $=18^{\circ}$, and the complicated stream cannot be modeled as accurately as that in the non-separation zone. These results altogether suggest that both models are reasonably accurate and that parameterized VGs can be used to replace solid VGs in CFD research.

\section{CONCLUSIONS}

Based on the lifting line theory and delta wing theory and considering the inter-effect of winglets, a parametric model of contra-rotating VG arrays has been developed in this study to estimate the maximum circulation of the wings with the N-S equations as an extra source term. The model was validated by comparison against experimental data in the cases of VGs equipped on a plate and a blade segment with five pairs of VGs.
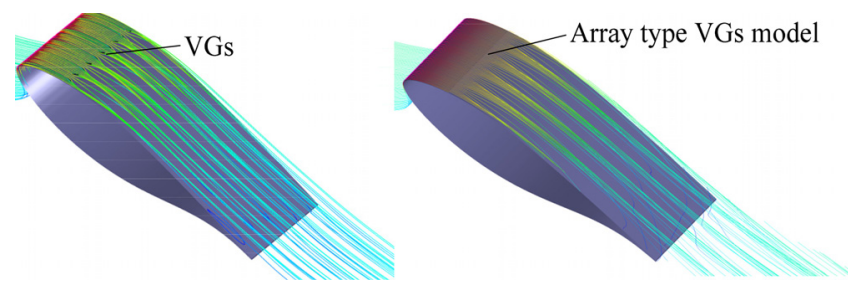

FIG. 14. Streamlines of solid VG and parameterized VG models at AoA $=16^{\circ}$. 

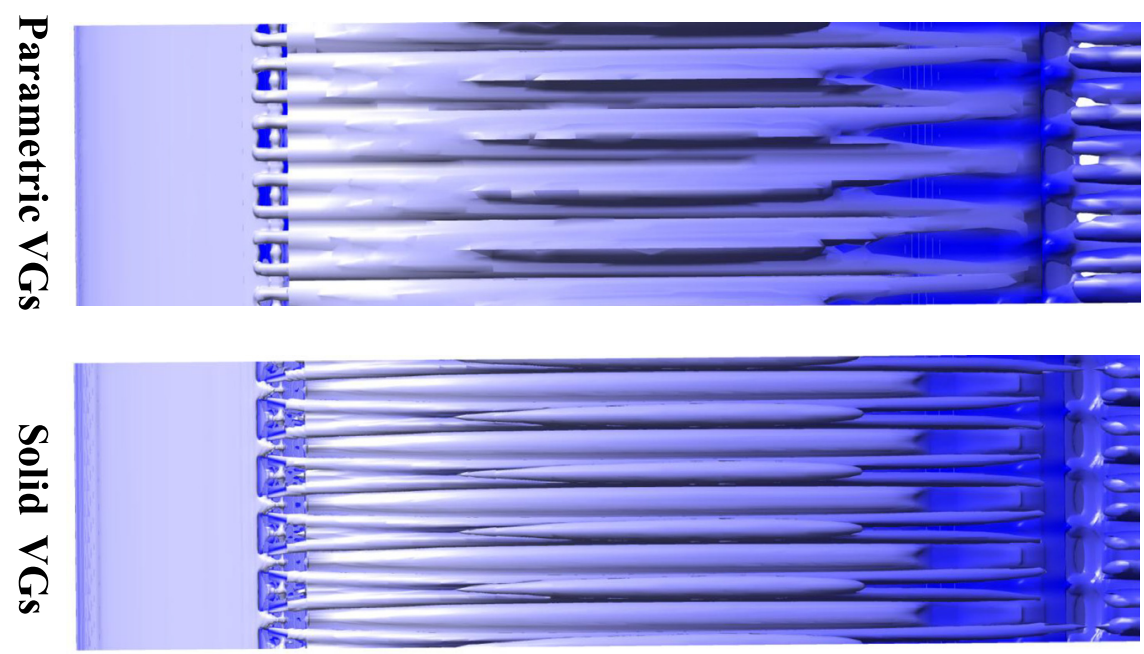

(a) $\mathrm{AOA}=5^{\circ}$
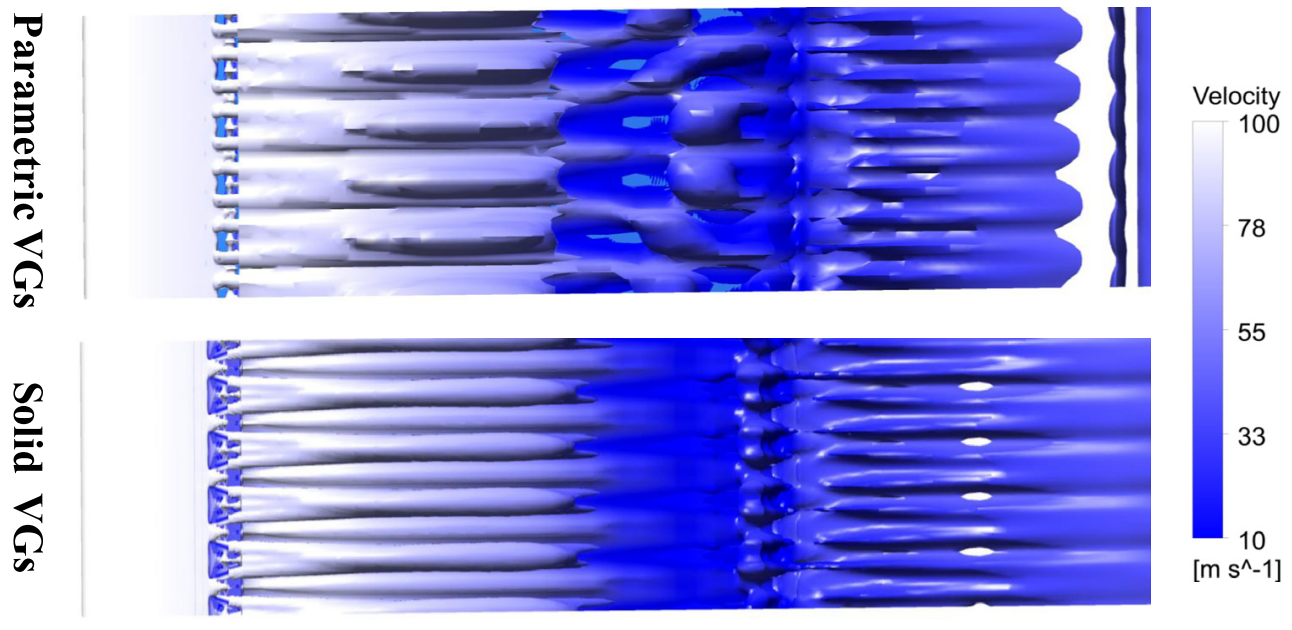

(b) $\mathrm{AOA}=12^{\circ}$
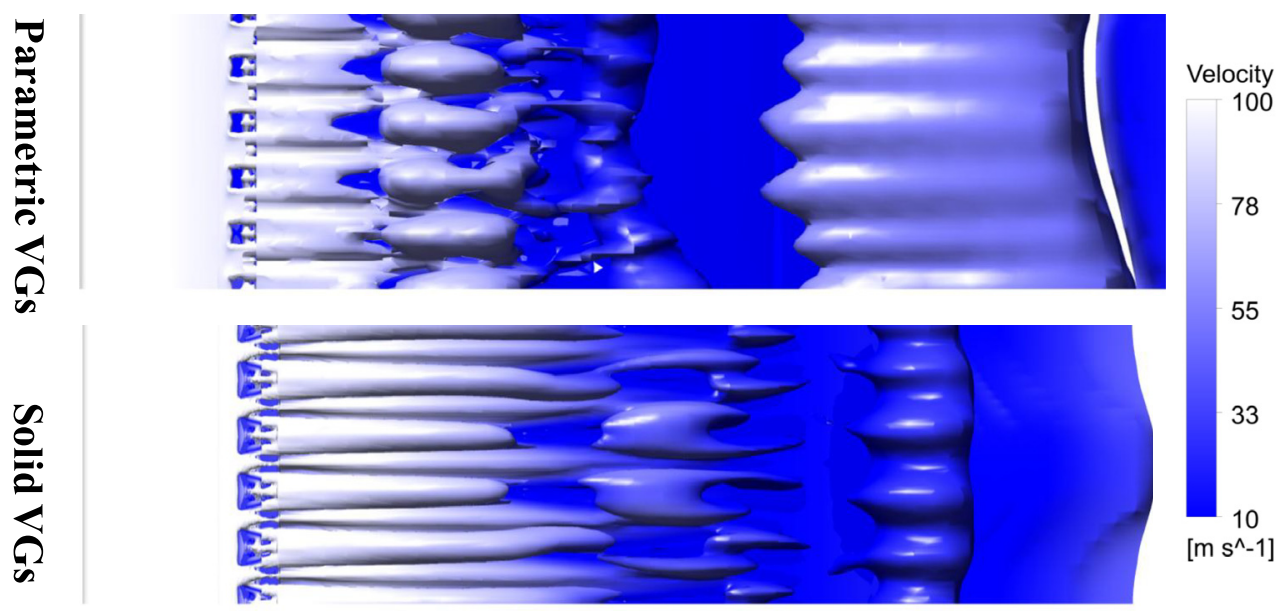

(c) $\mathrm{AOA}=18^{\circ}$

FIG. 15. Parametric modeling versus solid boundary modeling. 


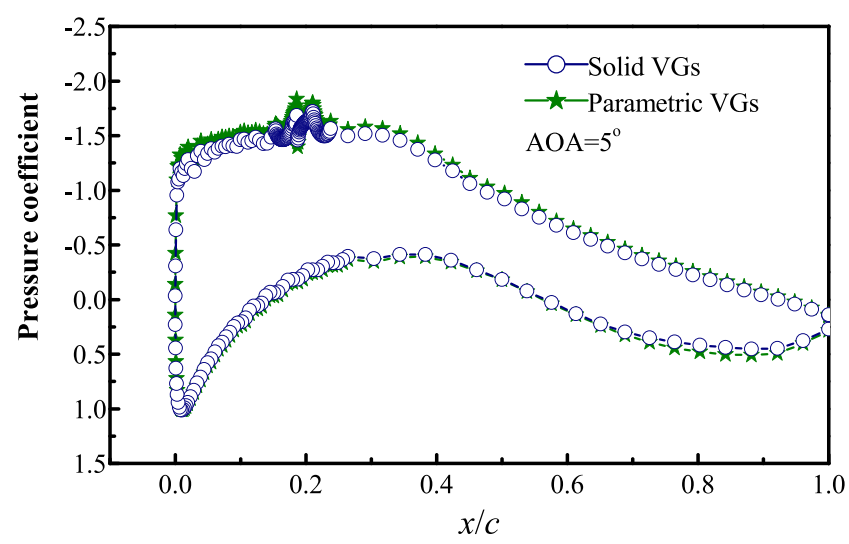

(a)

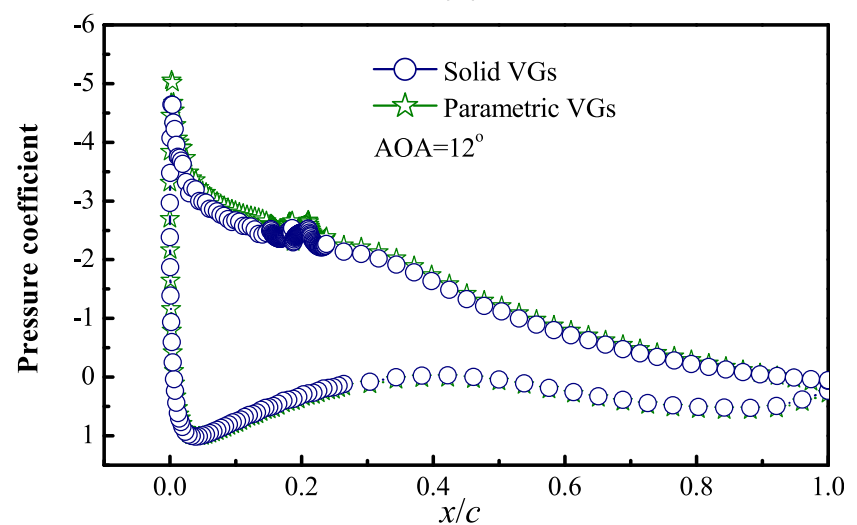

(b)

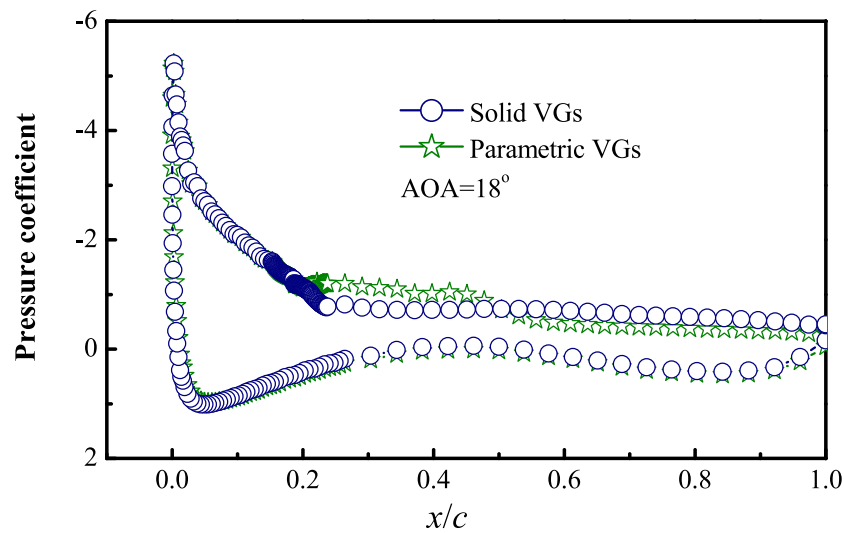

(c)

FIG. 16. Pressure coefficients between two CFD models.

(1) The array type parametric model is in closer agreement with experimental data than existing parametric VG models. The spacing of VGs has a significant impact on its circulation. The results of the single VG model deviate from the experimental data with a maximum error of $49.4 \%$ at $\alpha=20^{\circ}$. The maximum error of the array type VG model is $4.8 \%$ as $4^{\circ}<\alpha<18^{\circ}$ and is only $13.2 \%$ even at $\alpha=20^{\circ}$.

(2) A blade segment of a DU91-W2-250 aerofoil with five pairs of VGs has been modeled via the array type model and the single VG model for the sake of comparison. At $0^{\circ} \leq \alpha \leq 14^{\circ}$, there is little difference among the experiment results; the advantage of the former model is evident at $14^{\circ} \leq \alpha \leq 20^{\circ}$ with a dramatically higher accuracy. 
(3) The surface pressure coefficient and streamline results showed that the array type parametric model can be used to replace the solid VG model. The array type parametric model requires only $0.8 \times 10^{6}$ mesh points, i.e., far less than the $3 \times 10^{6}$ mesh points necessary for solid VG conditions.

\section{ACKNOWLEDGMENTS}

This paper was supported by the project of the National Natural Science Foundation of China, Grant No. 11502070, National Basic Research Program of China (“973" Program), Project No. 2014CB046200, Foundation Research Project of Jiangsu province (Natural Science Foundation), Project No. SBK201340780, and "Summit of the Six Top Talents" Program of Jiangsu Province, Project No. XNY-007.

\section{NOMENCLATURE}

a Distance of two points $y_{1} y_{2}(\mathrm{~m})$

A Area $\left(\mathrm{m}^{2}\right)$

AoA Angle of attack (deg)

$b \quad$ Wing span $(\mathrm{m})$

$c \quad$ Chord (m)

$C_{D} \quad$ Drag coefficient

$C_{D .12}$ Induced drag coefficient of VG1 due to VG2

$C_{L} \quad$ Lift coefficient

$C_{L \cdot P} \quad$ Coefficient of potential lift

$C_{L \cdot V} \quad$ Coefficient of vortex lift

$C_{L}^{\alpha} \quad$ Slope of the lift coefficient

$D \quad \operatorname{Drag}(\mathrm{N})$

$F \quad$ Force $(\mathrm{N})$

$K_{P} \quad$ Potential constant

$K_{V} \quad$ Wing vortex lift constant

$L \quad$ Lift, $N$; length of the annular region (m)

$M \quad$ Torque $(\mathrm{N} \mathrm{m})$

$q \quad$ Dynamic pressure $(\mathrm{Pa})$

$r \quad$ Radius $(\mathrm{m})$

$S \quad$ Vortex generator area $\left(\mathrm{m} \mathrm{s}^{-2}\right)$

$U \quad$ Free stream velocity $\left(\mathrm{m} \mathrm{s}^{-1}\right)$

$U_{\text {eff }} \quad$ Effective stream velocity $\left(\mathrm{m} \mathrm{s}^{-1}\right)$

$u_{12}$ Axial velocity of VG1 induced by VG2 $\left(\mathrm{m} \mathrm{s}^{-1}\right)$

$v \quad$ Induced velocity $(\mathrm{m} / \mathrm{s})$

$w \quad$ Normal component of induced velocity $\left(\mathrm{m} \mathrm{s}^{-1}\right)$

$x, y, z \quad$ Cartesian coordinates

$y_{1} \quad$ Point of VG1

$y_{2} \quad$ Point of VG2

Z Vortex generator spacing $(\mathrm{m})$

$\alpha \quad$ Angle of attack (deg)

$\alpha_{i} \quad$ Down wash angle

$\alpha_{12} \quad$ Angle of attack induced on VG1 by VG2 (deg)

$\beta \quad$ Geometric parameter (deg)

$\Gamma \quad$ Circulation $\left(\mathrm{m}^{2} \mathrm{~s}^{-1}\right)$

$\Gamma_{o} \quad$ Maximum circulation $\left(\mathrm{m}^{2} \mathrm{~s}^{-1}\right)$

$\varepsilon \quad$ Wing apex angle (deg)

$\Lambda \quad$ Vortex generator apex angle (deg)

$\lambda \quad$ Aspect ratio of vortex generators 
$\mu \quad$ Mean value

$\rho \quad$ Air density $\left(\mathrm{m}^{3} \mathrm{~kg}^{-1}\right)$

$\sigma \quad$ Efficiency factor (standard deviation)

\section{Subscript}

$b \quad$ Bound vortex

$i \quad$ Induced

im Image effect

$t \quad$ Trailing vortex

2D Two dimensional

$3 D$ Three dimensional

Bender, E. E., Anderson, B. H., and Yagle, P. J., "Vortex generator modeling for navier-stokes codes," in 3rd Joint ASME/ JSME Fluids Engineering Conference, San Francisco, CA, USA (1999).

Bragg, M. B. and Gregorek, G. M., "Experimental study of airfoil performance with vortex generators," J. Aircr. 24(5), 305-309 (1987)

Bray, T. P., "A parametric study of vane and air jet vortex generators," Ph.D. thesis (Cranfield University College of Aeronautics, 1998).

Booker, C. and Zhang, X., "Large-scale source term modeling of vortex generation," AIAA Paper No. 2009-3951, 2009.

Fernandez, U., Réthoré, P. E., Sørensen, N. N., Velte, C. M., and Zahle, F., "Comparison of four different models of vortex generators," in Ewea 2012-European Wind Energy Conference and Exhibition-Copenhagen, Denmark (2012).

Filgueira, P. M., Gamiz, U. F., Zulueta, E., Errasti, I., and Gauna, B. F., "Parametric study low-profile vortex generators," Int. J. Hydrogen Energy 42, 17700 (2017).

Godard, G. and Stanislas, M., "Control of a decelerating boundary layer. Part 1-Optimization of passive vortex generators," Aerospace Sci. Technol. 10, 181-191 (2006).

Houghton, E. L., Carpenter, P. W., Steven, C., and Dan V., Aerodynamics for Engineering Students, 6th ed. (ButterworthHeinemann, 2013).

Jirásek, A., "A vortex generator model and its application to flow control," AIAA Paper no. 2004-4965, 2004.

Jones, R. T., "Properties of low aspect ratio wings at speeds below and above the speed of sound," NASA Report No. 835, 1946, pp. 59-63.

Kunik, W. G., "Application of a computational model for vortex generators in subsonic internal flows," AIAA Paper No. 1986-1458, 1986.

Li, Z. W. and He, D. X., "Reviews of fluid dynamics researches in wind energy," Adv. Mech. 43(5), 472-525 (2013).

Lin, J. C., Robinson, S. K., and McGhee, R. J., "Separation control on high-lift airfoils via micro vortex generators," J. Aircr. 27(5), 503-507 (1994).

May, N. E., "A new vortex generator model for use in complex configuration CFD solvers," AIAA Paper No. 2001-2434, 2001.

Nikolaou, I. G., Politis, E. S., and Chaviaropoulos, P. K., "Modeling the flow around airfoils equipped with vortex generators using a modified 2D Navier-Stokes solver," J. Sol. Energy Eng. 127, 223-233 (2005).

Pauley, W. R. and Eaton, J. K., "An experimental study of the development of longitudinal vortex Pairs embedded in a turbulent boundary layer," AIAA J. 26(7), 816-823 (1988).

Polhamus, E. C., "A concept of the vortex lift of sharp-edge delta wings based on a leading-edge-suction analogy," NASA Technical Note D-3767, 1-18 (1966).

Polhamus, E. C., "Prediction of vortex-lift characteristics by a leading-edge suction analogy," J. Aircr. 8(4), 193-199 (1971).

Rao, D. M. and Kariya, T. T., "Boundary-layer submerged vortex generators for separation control-An exploratory study," AIAA Paper No. 88-3546, 1988.

Stam C. J., "Source term modeling of vortex generators," M.S. thesis (Denmark Technical University, 2016).

Taylor, H. D., "The elimination of diffuser separation by vortex generators," United Aircraft Corporation Report No. R4012-3, 1947.

Traub, L. W., "Prediction of delta wing leading-edge vortex circulation and lift-curve slope," J. Aircr. 34(3), 450-452 (1997).

Traub, L. W., "Theoretical and experimental investigation of biplane delta wings," J. Aircr. 38, 536-546 (2001).

Timmer, W. A. and Van Rooij, R. P. J. O. M., "Summary of the Delft University wind turbine dedicated airfoils," J. Sol. Energy Eng. 125(4), 488-496 (2003).

Troldborg, N., Zahle, F., and Sørensen, N. N., "Simulation of a MW rotor equipped with vortex generators using CFD and an actuator shape model," AIAA Paper No. 2015-1035, 2015.

Wendt, B. J., "Parametric study of vortices shed from airfoil vortex generators," AIAA J. 42(11), 2185-2195 (2004).

Wendt, B. J. and Reichert, B. A., "The modeling of symmetric airfoil vortex generators," AIAA Paper No. 96-0807, 1996.

Zhang, L., Yang, K., and Xu, J. Z., "Modeling of delta-wing type vortex generators," China Technol. Sci. 54, 277-228 (2011).

Zhao, Z. Z., Li, T., Wang, T. G., Liu, X., and Zheng, Y., "Numerical investigation on wind turbine vortex generators employing transition models," J. Renewable Sustainable Energy 7, 063124 (2015).

Zhao, Z. Z., Zeng, G. Y., Wang, T. G., Xu, B. F., and Zheng, Y., "Numerical research on effect of transition on aerodynamic performance of wind turbine blade with vortex generators," J. Renewable Sustainable Energy 8, 063308 (2016). 